\title{
REVIEW
}

\section{A Comparative Analysis of Sino-Thai College English Course Teach- ing__ A Case of Comparison between Jiujiang University and Chiang Mai University}

\section{Xiangbo Yu ${ }^{1^{*}}$ Yiping $\mathrm{Wu}^{2}$}

1.School of Foreign Languages, Jiujiang University, Jiujiang, Jiangxi, 332005, China

2.School of History and Culture, Jiangxi Science and Technology Normal University, Nanchang, Jiangxi, 330038, China

\begin{tabular}{l}
\hline ARTICLE INFO \\
\hline Article history \\
Received: 27 December 2019 \\
Revised: 8 January 2019 \\
Accepted: 9 April 2020 \\
Published Online: 16 April 2020 \\
\hline Keywords: \\
Comparative analysis \\
Jiujiang University \\
Chiang Mai University \\
College English course teaching for non-En- \\
glish majors
\end{tabular}

*Corresponding Author:

Xiangbo Yu

School of Foreign Languages, Jiujiang University, No. 551 Qianjin East Road, Jiujiang, Jiangxi, 332005, China;

E-mail: xuetongtian@126.com.

\begin{abstract}
English is one of the most common languages in the world, and it has become one of the most important subjects in various countries. The native languages of China and Thailand are not English, and both countries are located in Asia and have many similarities in geographical location and cultural background. The Ministries of Education of the two countries have successively put forward relevant policies to promote the development of English education in the country. The implementation of these policies has promoted the development of college English course teaching in the country. These factors determine that the two countries have similarities in college English course teaching for Non-English majors. However, there are differences in teaching mode and teaching staff in the two countries because of their different national conditions, which make many differences, exist in college English course teaching for non-English majors in the two countries.

During the author's career as an exchange student in Chiang Mai University, she experienced the difference of college English course teaching for non-English majors in Thai universities, so the author did some researches on the basis of the understanding of English course teaching in Thai universities. Therefore, this thesis takes Sino-Thai college English course teaching for non-English majors as the research object-takes Jiujiang University and Chiang Mai University as example, and analyses their present situation from the aspects of the development and evolution, the teaching mode, and teaching staff of college English course teaching for non-English majors. On this basis, the author makes a comparative analysis of the English course teaching for non-English majors in two selected universities, then find their respective advantages and disadvantages, and put forward some suggestions on the development of Sino-Thai college English course teaching.
\end{abstract}




\section{Introduction}

\subsection{Background and Significance}

\subsubsection{Background}

In recent years, with the deeper degree of globalization, the relationship between various countries is getting closer and closer, so the status and role of non-English majors who are proficient in English is becoming more and more prominent in the global market. The cultivation of talents who can comprehensively use English has attracted the attention of scholars. It is increasingly urgent to cultivate talents with global awareness, creativity and application ability. One of the most important ways to train English proficiency is college English course teaching for non-English majors. China is the largest developing country in the world, and its international status has been upgraded unprecedentedly. Although after years of development, college English course teaching for non-English majors in China has made great progress, there are still some problems. Therefore, there are relatively few talents who are proficient in English, which is out of line with the status of our country.

Thailand is a world-famous tourist resort, so a large number of tourists from all over the world come to Thailand for vacation every year ${ }^{[3]}$.Therefore; it attaches great importance to English education. English becomes its second official language. After a long period of development, its universities have accumulated a lot of good experience. From the perspective of cultivating English proficiency, this paper compares the Sino-Thai college English course teaching for non-English majors, and probes into their advantages and problems. Furthermore, the paper puts forward some methods which are beneficial to the cultivation of English proficiency and to the improvement of Sino-Thai college English course teaching for non-English majors.

\subsubsection{Significance}

The college English course teaching for non-English majors in China and Thailand has developed quite well. Under the background of globalization, the training of English-proficient talents is both market-oriented, so the demand for English proficiency is expanding day by day. College English course teaching for non-English majors is an important part for the cultivation of English proficiency. The university must consider the problems of discipline innovation, market demand and external factors, etc., and cultivate high-quality English learners who can adapt to the global market. Therefore, we can explore the similarities and differences of Sino-Thai English course teaching and their respective problems by comparing college English course teaching for non-English majors in Sino-Thai universities, and train talents with global awareness and better adapt to the demand of the international market.

\subsection{Direction and Methodology}

\subsubsection{Methodology}

This paper mainly adopts the methods of documentary analysis, comparative study, case study, qualitative analysis, date analysis and induction. First of all, the author compares the current situation of Sino-Thai college English course teaching for non-English majors through literature analysis. Secondly, the author selects two representative universities' English course teaching from China and Thailand as case study. Then the author will find the similarities and differences between the two countries' college English course teaching through the collection of relevant materials and my personal experience. Finally, the author will summarize the whole thesis and put forward some reasonable suggestions to improve the college English course teaching for non-English majors in the two countries.

\subsubsection{Direction}

According to the research background, this paper puts forward the theoretical and practical significance of the topic, and the research methods and ideas. By means of the methods of documentary analysis, comparative study, the author will make a comprehensive analysis of the current situation of college English course teaching for non-English majors in China and Thailand, and compares the similarities and differences between the two countries by reading monographs, newspapers and periodicals.

The first step is to describe "what is Sino-Thai college English course teaching like" by the method of documentary analysis. Second, because of the different national conditions, social culture, system, ideology and so on, there must be some differences in the setting up of education. Therefore, the method of "case description" and "comparative study" should be adopted. Then the author will summarize their similarities and differences. Finally, the author will find out their respective problems and give the relative solutions by the methods of induction.

\section{The Present Situation of Sino-Thai Col- leges}

\subsection{The present situation in Chinese Universities}

\subsubsection{Development}

In the early years of New China, the state attached great 
importance to Russian education, and ignored English education. Universities did not introduce English courses and put an end to this situation until the Ministry of Education issued the "Notice of College Foreign language" in 1956.

However, college English education was once again seriously damaged during the Cultural Revolution. It was not until the country carried out the reform and opening up that the college English education really developed. In 1978, the Ministry of Education held a national forum on foreign language education in Beijing ${ }^{[9]}$. The meeting summarized the experience and lessons of English education after the founding of New China, and discussed how to strengthen the construction of teachers and improve the teaching level of college English education, and then published "some opinions on strengthening foreign language education in colleges", and pointed out the way to the development of college English. Since then, the number of colleges offering English courses has increased year by year, the scale of universities and teaching quality have been greatly improved, the research of teaching theory and teaching methods has been developed rapidly, and the college English course teaching for non-English majors in our country has made great progress.

\subsubsection{Teaching model}

The teaching methods of college English course teaching for non-English majors in China are more classroom lectures, that is to say, most of the time the teachers expound in the platform, the students sit down, listen, and take notes. Because of the large number of students, open discussion in class is nearly impossible to carry out, the teaching method is single, students' option is weak ${ }^{[1]}$. In the conversational practice, students talk about a topic in English in group. While the listening class mainly depends on language lab. The freshmen and sophomores attend classes in order to lay a good foundation in English, while the juniors and seniors go to classes in order to improve their understanding of English articles ${ }^{[4]}$. English is the carrier of Western culture and a tool for transmitting knowledge and information. On the one hand, the Chinese teaching method cannot enlarge the students' vision. On the other hand, the students' abilities of investigation, getting information independently, thesis writing is not adequately trained ${ }^{[5]}$.

\subsubsection{Teaching Staff}

Most of the English teachers employed in Chinese colleges are selected from the outstanding college graduates trained in our own country. There are only a small number of na- tive English-speaking teachers. Chinese teachers share the same native language with Chinese students, and have their own profound experience about learning English. Their thinking patterns and language structures are highly simi$\operatorname{lar}^{[10]}$. These characteristics are helpful for teachers to accurately understand the difficulties and language approaches in the Chinese students' study, and to teach them according to their aptitude. But language is the carrier of culture: its most important function is the transmission and exchange of culture and knowledge. Native English teachers, whose English pronunciation is pure, can effectively promote the development of students' listening and speaking abilities. At the same time, if students have been nurtured by Western culture for a long time, they will inadvertently have the temperament of Western culture. It can help students to understand more deeply the western culture as a kind of strange culture, and to understand the way of thinking of the westerners. Therefore, in the Chinese college English course teaching for non-English majors, English-speaking and English-trained foreign teachers should be employed to enable students to experience the cultural style conveyed by the English language.

\subsection{The Present Situation in Thai Universities}

\subsubsection{Development}

Since the establishment of the Bangkok Dynasty - Thailand, successive kings have attached great importance to diplomatic relations, so they have paid great attention to the English study, and then set off an upsurge about learning English in Thailand ${ }^{[17]}$. The promulgation of relevant foreign policy has attracted a large number of Western missionaries to Thailand, and allowed missionaries to run schools in Thailand, and actively encouraged foreign teachers to work in Thailand. European modern higher education system was then introduced into Thailand. At the same time, the government has also set up scholarships to send overseas students to study in Western colleges. Since then, college English course teaching has developed rapidly in Thailand and become the main channel for people to learn Western civilization and innovation. As English plays an increasingly important role in the economy, society and national life, the higher English course teaching in Thailand presents various teaching modes. In 2002, bilingual international schools and English courses designed for students both at home and abroad became popular ${ }^{[11]}$. The number of English-speaking teachers increased, and their nationalities were diversified.

\subsubsection{Teaching Model}

In the Thai college English course teaching for non-En- 
glish majors, the teaching methods are more flexible and diverse. Students often sit around the teachers. The teachers often use the teaching methods of dialogue, interaction, exchange and discussion. At the same time, they try to train students' listening and speaking ability as much as possible, and let everyone participate in teaching activities as far as possible. Of course, the teaching methods also have their own characteristics, except that the subjects related to basic knowledge are taught in school teaching, it pays more attention to the students' abilities to use language to find information and communicate. Teachers often ask students to read more extracurricular books, to understand Western society and culture. They give students some questions and ask them to look up materials and information, and then investigate and express their opinions in the classroom and interact with everyone. Even if the teacher uses class lecture, he often introduces a lot of contents outside the textbook, which expands the students' vision and improves the students' abilities of reading, conversation and using English to acquire information autonomously.

\subsubsection{Teaching Staff}

Most College English teachers in Thailand are foreigners (English-speaking), which makes students, come into contact with authentic English. Students can only use English to communicate with teachers in the classroom, so they get many chances to practice English. So long-term training can effectively improve the students' listening ability. The teaching methods of foreign teachers are novel and diverse, such as group teaching, debates, special discussions, etc. These kinds of classroom activities are designed to be student-centered, which can enhance students' interest in learning and their desire for interaction. All of this, in a manner, can promote college English course teaching for non-English majors. However, there are also some problems such as short time of foreign teachers' employment, large mobility, laissez-faire in class, poor learning quality and so on.

\section{An Analysis of the Comparative Results}

\subsection{Reasons for Choosing the Two Universities}

There are four reasons of choosing Chinese Jiujiang University and Thai Chiang Mai University as the comparative colleges:

(1) The two universities are similar in size. They have more than 30,000 students and nearly 20 secondary colleges.

(2) The two universities have the same direction of talent training. Both are national comprehensive universities, and are oriented to market demand.

(3) Both universities regard English as the most important foreign language. The native languages of them are not English, but they regard English as the first foreign language.

(4) The communication between the two universities are frequent. Since 2003, they have been cooperating in exchange projects for 15 years. They have enhanced mutual understanding and deepened their friendship in the course of exchange.

Therefore, it is comparable that choosing these two universities as a sample of the comparison of Sino-Thai college English course teaching for non-English majors. At the same time, it can also promote the communication and mutual learning.

\subsection{The Contrastive Results}

\subsubsection{Similarities}

(1) College English course teaching in both countries started late, and gradually transformed from a backward state to present state, its teaching quality has improved. All of this cannot be separated from the support of national policies. In China, the Ministry of Education officially initiated the reform of college English course teaching in 2003, which required the adoption of advanced information technology in college English course teaching. In 2016, the syllabus indicated that college English course teaching for non-English majors mainly included English language knowledge and applied skills, learning strategies and cross-cultural communication. In Thailand, Rama V Chulalongkorn built a new school in the Royal Palace, and employed Anglo-Americans as teachers. In 1990, the Thai government introduced the reform program of college educational curriculum, which required opening 9 foreign languages, including English. In 2008, the Ministry of Education of Thailand issued the Core Curriculum of higher Education. English was listed as one of the basic courses in higher education ${ }^{[18]}$. There are more than a dozen kinds of English courses as compulsory and optional courses in college education.

(2) College English course teaching in both countries has gradually improved the teaching form: from the single mode of classroom teaching to the diverse teaching mode based on discussion, debate and communication. It has strengthened the cultivation of listening and speaking ability on the basis of the previous emphasis on literacy to better meet the undergraduates' demand for English learning. The previous courses changed from reading and writing to reading, writing and listening, then went over into reading, writing, listening, speaking, and translating, 
and transit into reading, writing, listening, speaking, translating, audiovisual learning now.

(3) College English course teaching for non-English majors in China and Thailand pays more attention to the role of foreign teachers in the construction of teachers, and constantly seeks the best balance between the number of indigenous English teachers and foreign teachers. The proportion of foreign teachers in Thai universities is increasing year by year, while the number of foreign teachers in China has increased rapidly since the 2008 Olympic Games. Both countries are actively looking for countermeasures to solve the problems existing in teachers of college English course teaching for non-English majors.

\subsubsection{Differences}

(1) Thailand is a world-famous tourist country. People from all over the world have to communicate in English, so English has become the only foreign language funded by the Thai government ${ }^{[16]}$. Most Thais can read English. For example, many people in Chiengmai communicate in English, which creates abundant opportunities for college students to use English. In China, English is as important as Chinese and mathematics. But many students are not good at English, and only a few of them can communicate in English normally. Although many foreign friends come to China, their number is still very small compared with the China's large population. Therefore, it is difficult for Chinese college students to find opportunities to communicate with those foreigners.

(2) The two countries have different national conditions. Since 2000, in order to improve the efficiency of English course teaching, most universities in Thailand have generally divided students into small classes according to their professions and standards, and limited each class in 10-20 people ${ }^{[12]}$. College English course teaching in China has a large number of teaching objects: 30 to 50 students, so it is difficult for teacher to teach by means of discussion and debate ${ }^{[19]}$. Most activities are confined in one single classroom. But the construction and utilization of network in China can solve the malpractices of large class in college English course teaching for non-English majors, and at the same time, it can also improve the quality of college English course teaching for non-English ${ }^{[8]}$.

(3) "Investigation of Current Situation" provides the status of college English teachers in China. Among the 467 universities that provide data on the professional titles of college English teachers, the status of teachers' titles is as follows: the number of professors is 702 , accounting for $3.3 \%$; the number of associate professors is 4,761 , accounting for $22.6 \%$; the number of lecturers is 15587 , accounting for $74.1 \%$. The total number of teachers in
457 universities providing data on the academic qualifications of college English teachers is 21065. Among them, the number of teachers with doctorate degree is $1.5 \%$ and the number of teachers with master degree are $60.1 \%{ }^{[13]}$. These data show that the structures of professional title and educational background of college English teachers in our country are not balanced. All of these factors are not conducive to teachers' individual development and affect the quality of college English course teaching. Thai college English teachers are foreign teachers and native teachers, but the number of foreign teachers is much higher than that of native teachers. The proportion of foreign teachers is $88 \%$. Foreign teachers are employed to teach English in universities, which gives students the chance to communicate with authentic English. Students can only communicate with their teachers in English in class, which creates many opportunities for students to communicate directly in English.

\subsection{Problems Existing in Jiujiang University}

\subsubsection{Predominant Standardized Testing}

Most of the English course teaching for non-English majors in Jiujiang University is in large class with dozens of students, so teachers have to choose the easier way to score, such as attendance and times of making the speech in class, with final exam amounting to the most part, which is difficult for each student to get the objective and accurate evaluation. In short, English teaching still relies on summative evaluation. Students' scholarship linked with their scores in the summative evaluation, which objectively leads them to focus on the standardized examination, rather than further study western culture and develop communicative competence in English. This makes the college English course teaching for non-English majors deviate from the humanistic concern. Therefore, it is difficult to train excellent talents who have a good command of major and English.

\subsubsection{Single Teaching Way}

Public English course teaching methods in Chinese universities are single. At present, Jiujiang University generally uses method of the "word-grammar-translation" in English teaching: teachers explain word and grammar, students take notes. This method is tedious and difficult to bring up students' interest in learning English, thus it indirectly causes students' weariness to English learning. Wu Qidi, deputy minister of education, pointed out:

For many years, our foreign language teaching has maintained the classroom teaching mode in which teachers speak and students listen, modern educational tech- 
nology has not been fully utilized. Even if teachers use multimedia teaching, most of them only stay at the level of moving the blackboard onto the screen. It is also not conducive to the cultivation of students' comprehensive ability in English application ${ }^{[6]}$."

\subsubsection{Large Class}

Since Jiujiang University has been expanding its enrollment year after year, the scale of class has also expanded. There are significant individual differences in students' English foundation, interest in learning, personality, intelligence and learning strategies, so teachers are tired of coping with many problems in public English classes with more than 60 students. For example, in large class, it is difficult to realize timely communication and interaction between teachers and students and impossible for teachers to answer the questions raised by every student. Therefore, lack of communication between teachers and students makes it difficult for teachers to understand the actual learning situation of most students. The result is that students can't put what they learned into action, teachers have low teaching efficiency, which will eventually result in the time spending in learning English is not proportional to the practical result.

\subsection{The Problems Existing in Chiang Mai Univer- sity}

\subsubsection{Unreasonable Management System About Teachers}

In recent decades, the scale of Chiang Mai University has expanded dramatically, which results in the number of teachers are insufficient and heavy workload for teachers. In addition, at this stage, foreign teachers' resources are still in short. How to attract foreign teachers is still a major task of Chiang Mai University. In terms of improving the quality of teachers, the university still does not pay enough attention to it and cannot attract teachers to transfer from teaching to teaching scientific research. Teachers' low academic standards directly lead to students' poor English. In 2002, the government stipulated that university teachers are no longer civil servants, but collegiate employees who enter into contracts with the universities ${ }^{[15]}$. English as an optional course in university, it's teachers, students and classrooms have great mobility-change once a term, which result in less communication between teachers and students, and difficulties in teaching management for teachers ${ }^{[7]}$. Therefore, teachers' sense of duty weakens.

\subsubsection{Backward Teaching Conception}

Public college English course teaching in Chiang Mai
University has the tendency of simply copying foreign models, leading to the development of its English education divorces from the level of national economic development and can not keep pace with society. Moreover, because Thailand adheres to a centralized educational management system, so universities lack of flexibility and autonomy, and public English course teaching is too rigid to be applied to practical work and life.

\subsubsection{Unsound Test Mechanism}

The text system of Chiang Mai University refers to the Western scoring method: $30 \%$ final grade add $70 \%$ regular grades. Of course, this scoring method is more reasonable than the examination system that heavily relying on summative evaluation. However, there are many potential problems: the regular grades mean the average scores of multiple regular examinations which greatly increases students' study burden. Students blindly do exercise, pursue exam results and ignore the accumulation of experience and the training of other ability.

In addition, teachers' tasks have been increased, and most of them pay attention to the test, rather than the students' normal performance and the practical application of English. Thus students are unable to meet the demand of society.

\section{Improving Methods}

\subsection{Improving Methods of Jiujiang University}

\subsubsection{Usage of Application-Oriented Evaluation System}

Universities should adhere to the application-oriented evaluation system, which, to a certain extent, will return foreign language learning to a normal state, remove the negative effects of excessive examinations, and restore the pleasure of foreign language learning ${ }^{[2]}$. It is possible for students to develop lifelong learning of a foreign language by using language for a variety of communicative activities, both oral and written and to gain satisfaction and pleasure in language learning.

\subsubsection{Reformation of Teaching Methods}

The reform of foreign language course teaching methods must be carried out in accordance with the students' learning conditions in Jiujiang University. The reform of course teaching methods is an important way to achieve the teaching aims, so course teaching should be "student-centered".

In terms of course teaching methods, cognitive linguistics holds that language learning is a process of contin- 
uous combination of new and old language knowledge, and the acquisition of language competence is a process of transforming language knowledge into automatic application $^{[14]}$. To realize this kind of combination and transformation, the classroom teaching should be concise, the content should be comprehensive and novel, students should do a great deal of practice.

\subsubsection{Development of the Students' Self-Study Ability}

Independent study is based on open education, and uses the learning system of distance education and centers on students to realize individualized learning. This unique learning model pays more attention to the characteristics and needs of students and attaches importance to the joint development of learning process and learning resources. It is the key to solve many problems such as large class teaching and the individual differences of students.

\subsection{Improving Methods of Chiang Mai University}

\subsubsection{Reformation of Management System About Teachers}

In order to solve the problems exists in Thai college public English teachers; the government should enlarge the number of the teaching staff. The following measures should be taken: university actively attract public English teachers with both political integrity and ability. The government should further increase the investment in education, especially in the field of scientific research. Universities should also pay attention to raising funds so as to attract more talented people into the ranks of education. In order to solve the problem of high fluidity of public English teachers, universities should define the courses and student groups that are most suitable for each teacher to teach. Moreover, the students choose the right teachers, so the stability of teachers is enhanced, which is helpful for teachers to draw up teaching plan and make the teaching more targeted and reasonable.

\subsubsection{Renovation of Teaching Conception}

The mode of teaching English behind closed doors can no longer meet the needs of economic, social and cultural modernization. In order to realize the modernization of English course teaching, it is necessary to change the traditional teaching notions, teaching aims and training target and boldly learn from the advanced educational concepts and teaching models of English teaching in other countries. In order to adapt to the rapid development of Thailand, college English course teaching for non-English majors must do a good job in public English teaching. It is necessary for university to pay attention to students' learning, to encourage them to participate in relevant English practice activities, and put the cultivation of students' practical competence and personalization in the most important position.

\subsubsection{The Optimization of Examination Mecha- nism}

The assessment method of English study adopted by Thai universities at this stage still cannot effectively reflect the students' command of English. In view of this, the assessment of English study should be more continuous and diverse. That is to say, when university examines the students' abilities, it should not only focus on the students' mastery of vocabulary and grammar, but also take into account the students' flexibility in using English and their innovation, and emphasize the students' abilities to apply English in their practical work and life, such as English interview and so on. Therefore, the English test must take the differences of students' abilities into account, ensure a comprehensive and effective assessment about students' English abilities in listening, speaking, and reading and writing, pay attention to the students' practical application, and reduce the tests. University should explore students' potentialities, and make an effective evaluation about students' ordinary performance.

\section{Conclusion}

Today, with the deeper degree of internationalization, English is increasingly important, so the position of English-proficient talents is becoming more conspicuous.

Compared with the English course teaching for non-English majors in Chiang Mai University, Jiujiang University has single teaching way, large class and many different evaluation methods that all rely on standardized testing. The purpose of this comparative analysis is that Jiujiang University can absorb Chiangmai University's quintessence and learn lessons from its inadequacies and do better in cultivating highly qualified English-proficiency with global awareness. In contrast to the practice of Chiang Mai University, the English course teaching in Jiujiang University should pay attention to the rational allocation of resources, and take students' learning situation and market demand into account. Jiujiang University should weak the leading role of examinations, so as to embody humanism in English course teaching and make use of modern technology to make up inadequacies cause by lack of drilling in real context to improve the effectiveness of college English course teaching. I believe that in the near future, there will be new breakthroughs and prog- 
ress in college English course teaching.

\section{References}

[1] Aimin Liang, Yan Chen. Development of College English Teaching in China under Needs Analysis[J]. Beijing: Higher Education of Social Science, 2012:22-23.

[2] Chen Xiujuan, Zhang Fengjuan. A Comparative Study of Foreign Language Education in China and The United States[J]. The Study of the High Education in Heilongjiang Province, 2013(9):57-59.

[3] David Hayes. The Value of Learning English in Thailand and Its Impact on Thai: Perspectives from University Students[J]. USA: Asia Pacific Journal of Education, 2016:73-74.

[4] HuYue. A Comparative Study of College English Syllabus between China and Japan[D]. 2015:67-68.

[5] Liang Sha. A Comparative Analysis of Chinese and American Higher Education Models[J]. Navigation of Literary and Scientific, 2017(11):45-47.

[6] Lu Mimi. The Present Situation, Problems and Countermeasures of Chinese College English Teaching[J]. Lyceum, 2014(14):87-90.

[7] Ma Bingqiong. On the Problems and Enlightenment of Higher English Education in Thailand[Z]. Around Southeast Asia, 2013:65- 67.

[8] Qian Shen. An Introduction of English Language Education in China: from Theory to Practice [J]. China: Overseas English, 2016(17):56-57.

[9] Ren Chi, Yu Hao. Current College Public English
Study in China[J]. Beijing: Higher Education of Social Science, 2013:77.

[10] Song Yingxiu. A Comparative Study of Japanese Education between China and Japan $[\mathrm{J}]$. Lyceum, 2015(7):98-100.

[11] Sukamoison. English Language Education Policy in Thailand[J]. Thailand: Asian English, 2016:69.

[12] Tan Xiaojian. The Evolution, Characteristics and Trend of Diversified Foreign Language Education in Thailand[J]. Around Southeast Asia, 2015:56-58.

[13] The Investigation of Present Situation, 2012:34-40.

[14] Wang Di. The Present Situation of ESP Teaching in Universities and the Reform of English Teaching[J]. Education for Chinese After-school (Theory), 2012(24):87-89.

[15] Wang Jinjun. The Development Characteristics and Trends of Thailand's Pluralistic Foreign Language Education Policy[R]. The Research of Comparative Education, 2011(9):56-57.

[16] Xia Li. A Comparative Analysis of English Educational Culture between China and Thailand[N]. Journal of Guangxi Education College, 2015(5):99.

[17] Yoshihide Sakurai. University Education and Area Studies in Northeastern Thailand[N]. Japan: Contemporary Sociological Studies, 1998:87-88.

[18] Zhang Hua. On the Core Curriculum[J]. Foreign Educational Datum, 2000(5):58-59.

[19] Zeng Dazhi. The Comparison of College English Education between China and Korea[N]. Journal of Xiangnan University, 2015, 36(1):104-106. 